\title{
Asociatividad y competitividad, una aproximación
}

\section{Associativity and competiveness, an approximation}

\author{
Berumen, Sergio y Octavio Palacios Sommer (2009), \\ CompetitiVidad, Clusters E INNOVACión, Trillas, MÉXico, IO3 PP., \\ ISBN: 978607 I7 OOI 55 .
}

Este libro aborda la competitividad, los clusters y las formas organizacionales orientadas a lograr o impulsar la innovación y la competitividad, los autores sostienen que éstas son características de la economía global actual, por lo que es necesaria su comprensión. De esta manera, dedican el libro a este objetivo, en el que buscan explicarlas de un modo sencillo, enfatizando su operatividad. Por cierto, desde hace unas décadas estos temas son parte del debate y la agenda de los gobiernos, organismos multilaterales, regionales, empresariales, de la sociedad civil y de la academia.

Los autores organizan el libro en tres capítulos, que pasamos a revisar en sus puntos más logrados.

El primero aborda la competitividad, para lo cual presentan varias aproximaciones conceptuales de este tema, las formas en que se puede medir y los instrumentos para desarrollar la competitividad local. Luego revisan tres formas de medición de la competitividad: el índice de tipo de cambio real efectivo, el de la revista The Economist, el World Competitiveness Yearbook, The World Economic Forum (WEF) y el análisis de competitividad de las naciones (CAN).

Sostienen que la competitividad local está en la base del auge o decaimiento de una localidad, que hay elementos que pueden fortalecerla: el espacio (en el que se considera el físico, los flujos de información o ciberespacio, los valores de la localidad o región), la causación acumulativa (en cómo la inversión puede tener efectos colaterales incrementales), la difusión de la competitividad por medio de los conglomerados (en los que puede influir la densidad poblacional, la apertura o predisposición a asimilar nuevos conceptos y procedimientos), la existencia de procesos evolutivos (que conforman rutinas, hábitos y habilidades, según el ciclo de vida empresarial). En OCDE (2002) encontramos referencias y ejemplos europeos de desarrollo local. La existencia y conjunción de los elementos mencionados favorecen la formación de sistemas competitivos.

Los autores señalan que hay otros elementos que favorecen la competitividad: los acuerdos y colaboración local, la identificación de las forta- 
lezas y limitaciones para adquirir y adaptar nuevos conocimientos, la proximidad entre las localidades pequeñas que permiten dedicar menos tiempo a desplazamientos y más a actividades importantes, la existencia de un entorno no conformista, progresista y pluralista, que las propuestas estén acordes con el medio y a atraer inversión hacia las fortalezas presentes y futuras. Considerando lo anterior, se está en la posibilidad de formular la estrategia local de desarrollo, para ello deberían considerarse varios escenarios, obtenidos de regresiones a partir de la visión a futuro, que servirían para elaborar las políticas y acciones. Caben varias estrategias, en la estrategia u opción de giro de paradigma, se busca cambiar las estructuras, en parte atrayendo a la inversión extranjera. La estrategia o perspectiva radical postula que el cambio debe apoyarse en las fortalezas locales, mientras que la incremental propone mejorar la competitividad con base en las fortalezas locales pero con apoyo público. Señalan también que el desarrollo local es más bien un objetivo a largo plazo, por lo que no siempre se tendrán resultados rápidos.

En el segundo capítulo se estudian las organizaciones y los clusters, los orígenes de las organizaciones, las razones de existencia de los clusters, así como algunas formas de clasificarlos y elementos que pueden ayudar a su desarrollo.

Se menciona que la evolución de la humanidad, de las organizaciones, ha estado ligada a los cambios tecnológicos, y que esta relación se puede analizar desde varios puntos de vista. Uno es el de la selección natural, es decir, las organizaciones pueden interpretarse como respuestas, adaptaciones, a los cambios del ambiente, explicación que resulta un tanto determinista. Otro enfoque sostiene que hay patrones regulares de avance del conocimiento tecnológico y que en ciertos momentos pueden darse rupturas, que luego se formalizan. Que en las organizaciones y clusters existen rutinas, patrones de conductas regulares, a veces formalizadas, que los individuos tratan de reproducir asimilando información; en el proceso de aprendizaje pueden producirse efectos negativos o positivos, que es posible formalizar y adoptar. Según la evolución lamarckiana (Jean Baptista Antoine de Monet, Caballero de Lamarck), al interactuar en las organizaciones, los individuos asumen funciones y crean cultura y dada su capacidad de desear una conducta o escenario futuro, con grados de incertidumbre, se les presenta la necesidad de planificar, lo que a su vez genera e induce cambios. En otras palabras, la innovación se puede entender como resultado de cambios inducidos y planificados, en ciertos casos revolucionarios, aleatorios y derivados de la interacción ambiental, tecnológica y económica.

Otro concepto que puede ayudar es el de la complejidad y el caos, que explica la aparición de los sistemas complejos a través de la autorganización, de la selección natural, en el que se transitaría del caos al orden natural, a 
pasos lentos; estos sistemas se relacionarían con el exterior mediante intercambios, conformando un número de subsistemas interactuantes que coevolucionarían determinándose conjuntamente. Esto puede generar inestabilidades que provocarían la aparición de organizaciones y estructuras nuevas, en casos por sucesos aleatorios que generarían indeterminación en la autorganización; las trayectorias podrían presentar bifurcaciones o no; así el futuro se crea o gesta a lo largo de un proceso evolutivo.

Es posible considerar a la sociedad como un sistema no lineal, donde las acciones de los individuos pueden influir en la sociedad; la globalización ha incrementado esta interacción. Esto nos lleva a enfoques schumpeterianos, a considerar lo micro, lo individual, el aprendizaje, la evolución, la selección, la racionalidad parcial, la heterogeneidad, la información incompleta, los incentivos, el monitoreo y las normas. Las rutinas y la creatividad pueden ayudar, pero en algunos casos pueden convertirse en lastres. Es decir, el progreso debe combinar la estabilidad y el cambio, la planificación y la espontaneidad; se necesitan sistemas flexibles que permitan la planificación y la creatividad.

Las organizaciones y los clusters se pueden ver como respuestas organizacionales a los cambios, registran interacciones internas y externas, en evolución. Éstas tienen objetivos y forman rutinas, pero considerando lo lamarckiano, podrían modificarse y a su vez cambiarían a las organizaciones. Los clusters se caracterizan porque son ambientes de información tácita compartida y presentan economías externas; los polos de desarrollo podrían potenciarlos.

Los clusters se conforman por dos motivos importantes: estratégicos (logro de sinergias, mejora de la posición competitiva, flexibilidad, cabildeo, manejo de información y conocimientos) y operativos (compartir costos, adquisición de habilidades, economías de escala y alcance, mejores condiciones con proveedores o clientes). Se caracterizan por la búsqueda de objetivos comunes, la confianza, la reciprocidad, la cooperación e interdependencia de los agentes. Ciertas condiciones ambientales locales pueden favorecer su desarrollo: la existencia de una cultura cooperativa y asociativa, el conocimiento tecnológico acumulado y el relevante para la innovación, el ambiente favorable para la innovación, el aprendizaje interactivo, la capacidad de influencia en el gasto público, la existencia de entidades privadas y públicas de apoyo, la existencia de relaciones entre las universidades y centros de investigación con el sector productivo. Además hay que considerar la interacción entre las características tecnológicas del sector, las estrategias de las empresas y las del cluster.

¿Cómo clasificar a los clusters?, hay varias posibilidades. Una se basa en la combinación de la arquitectura de los productos y la articulación y la complejidad de la tecnología, de modo que se tendría clusters tradicionales basados en la subcontratación, en el ensamblaje, en productos 
complejos, en innovación y desarrollo; en cada categoría se pueden considerar además cuestiones como los flujos de información, la complejidad tecnológica, el aprendizaje, el esfuerzo innovador, la gobernabilidad. Otra clasificación se fundamenta en la tecnología de las empresas: las que se basan en recursos naturales, los abastecedores predominantes de la oferta, los escalas intensivas, información intensiva, especialización en la oferta, conocimiento intensivo. Una tercera clasificación: clusters industriales, clusters locales, distritos industriales y redes de negocio. Y una final, en clusters centrales, complementarios y dependientes.

Un planteamiento para lograr el desarrollo económico es invertir en los sectores o actividades que tengan los mayores eslabonamientos posibles, pues así se tendría mayor repercusión. Al respecto, dado que los clusters suelen registrar eslabonamientos importantes, están concentrados sectorial y geográficamente, comparten dinamismo e innovación, algunos se relacionan con cadenas productivas globales, lo que sería una opción importante para el desarrollo. Debe mencionarse que los clusters pueden aparecer también en el sector público, universidades, centros de investigación, organismos no gubernamentales. Dini et al. (2007) hacen una revisión de experiencias latinoamericanas de clusters, arreglos territoriales y asociatividad; un tratamiento conceptual de competitividad, asociatividad y desarrollo local se encuentra en Vázquez (1999).

En el capítulo 3, los clusters se abordan como generadores de competitividad, enfocándose en la cooperación entre organizaciones, que aparecen para complementar fortalezas y superar sus limitaciones, al respecto es importante la estructura de la cooperación.

Al considerar los tipos de estructura de cooperación, se obtiene el modelo estático y dinámico de relaciones para la innovación y la competitividad, que presentan limitaciones por lo que abordan formulaciones más complejas, dos de competitividad y dos de innovación. El modelo de competitividad de Porter explica los factores que influyen en la competitividad y en la innovación. En el modelo de sistema nacional de innovación se busca estudiar y entender la evolución de las industrias dedicadas al desarrollo de alta tecnología y su relación con la sociedad, en el que se distinguen tres niveles.

El modelo de la triple hélice sostiene que las interrelaciones entre las empresas, el gobierno y las universidades generan una espiral o convergencia de investigación y desarrollo, un círculo concéntrico o capa emergente de las relaciones de mayor contenido. Además se debe considerar a los agentes, las instituciones y leyes o normas. La convergencia hace que, por ejemplo, algunos investigadores se conviertan en empresarios o que éstos se acerquen a las universidades para crear conocimiento, así como que los investigadores acudan a las empresas para conocer sus problemas y que los funcionarios públicos se acercan a las universidades y empresas. 
Este modelo es muy utilizado para la creación de parques de investigación y tecnológicos, en el que las interrelaciones se van formalizando y aumen$\tan$ en contenido.

El modelo de la competitividad sistémica considera los niveles meso (infraestructura, educación, tecnología), meta (factores socioculturales, valores), micro (estrategia empresarial, gestión, producción, asociatividad) y macro; y que todos inciden en la competitividad e innovación, así por ejemplo, la competitividad de una empresa depende de la competitividad del cluster. El modelo considera importante la confianza, lo cultural, lo local, el aprendizaje individual y colectivo, la existencia de centros tecnológicos. Requiere compromisos y lazos fuertes entre las partes, en los niveles nacionales, regionales y locales. Para la competitividad es importante además del precio y los costos, el esfuerzo interno, la confianza y lo cultural.

Finalmente los autores revisan tres casos de gestión de la innovación y competitividad, dos proyectos binacionales en la frontera norte de México y uno de California, en Estados Unidos, presentando los objetivos, estrategias y resultados de un modo compacto. Estas iniciativas se formaron para alentar la competitividad e innovación local y el desarrollo local, muestran que se puede colaborar, además de tener resultados colaterales, como una fuerza de trabajo más calificada, atracción de inversión, mejores funcionarios, generación de conocimiento, investigación y aplicación, sinergia. Al respecto recomiendan que cada integrante tenga claro qué espera y qué aportará, que establecerá acuerdos y cooperará, que los compromisos sean fuertes y a largo plazo, que en lo posible tengan independencia del ciclo político, que la visión sea de largo plazo y que surgirán nuevas formas de organización.

Esquemáticamente el libro es una buena propuesta sobre la competitividad (sobre todo local) y la asociatividad (clusters, arreglos territoriales), aunque con ciertas limitaciones. El objetivo de poner los conceptos a un nivel de divulgación se logra, si entendemos que se dirige a un público universitario, pues abundan conceptos y modelos, aunque no siempre bien explicados y desarrollados con la secuencia debida. En el capítulo uno, en su segunda parte, se desarrollan aspectos que alientan la competitividad local, no la general (OCDE, 2002), para detalles sobre desarrollo local y ejemplos. El capítulo tres aborda modelos para la competitividad e innovación, y no tanto los clusters, como es su primer título, y en los ejemplos se presentan acuerdos o arreglos territoriales y no los referidos a clusters, casos para los primeros se presentan en Corona (2005) y para los segundos en Dini et al. (2007). Así, no hay un buen manejo de los títulos de los capítulos, ni de ciertos desarrollos en su interior, que no abonan a la claridad y sencillez prometida. 


\section{Bibliografía}

Corona, Leonel (2005), México: El reto de crear ambientes regionales de innovación, Fondo de Cultura Económico, México.

Dini, Marco, Carlo Ferrero y Carolina Gasaly (2007), Pymes y articulación productiva, resultados y lecciones a partir de experiencias en América Latina, CePAL, Santiago de Chile.

oCDE (Organización para la Cooperación y el Desarrollo Económico) (2002), Mejores prácticas de desarrollo local, unesco, México.

Vázquez-Barquero, Antonio (1999), Desarrollo, redes e innovación. Lecciones sobre desarrollo endógeno, Pirámide, Madrid.

Recibida: 25 de noviembre de 2009. Aceptada: 30 de noviembre de 2010.

William Fernando Valdivia-Altamirano Universidad Autónoma del Estado de Morelos,

Campus Oriente Correo-e: wvaldi@uaem.mx

William Fernando Valdivia-Altamirano. Es doctor por la Universidad Autónoma de Madrid, estudió su licenciatura en la Universidad Nacional Agraria La Molina, Perú. Es profesor-investigador de economía en la Universidad Autónoma del Estado de Morelos, Campus Oriente. Sus líneas de investigación son: competitividad, proyectos y microfinanzas. Sus últimas publicaciones son: "Innovación, emprendimiento y redes: algunas propuestas ante la crisis, por el crecimiento con equidad", en Ludgar Meling Paredes Hernández (ed.), Retos de México ante las nuevas estructuras nacionales e internacionales, Universidad Internacional, Cuernavaca, pp. 19-29 (2009); "La competitividad, las políticas el emprendimiento y las universidades", Memorias del $2^{\circ}$ Coloquio Investigación Social y Administrativa en el Campus Oriente", UAEM, pp. 113-120 (2007); "La Comunidad Andina de Naciones. Balance de la integración andina abierta", Anuario de la División de Ciencias Sociales y Económico Administrativas, Universidad de Quintana Roo, Campeche, pp. 117-129 (2003). 